\title{
Mit dem Gehlift in die Berge
}

\section{Iris Ritzmann}

Prof. Dr. med. et lic. phil, Universität Zürich, Mitglied der Redaktion Medizingeschichte
Wundere Dich nicht, wandere! Mit diesem Slogan rief vor vielen Jahrzehnten die Üetliberg- und Sihltalbahn zum gesunden Wandern auf, illustriert mit einem beleibten Herrnauf einer Waage. Das Wandern in der gesunden Schweiz bildete bereits damals als Fitnessübung in den Sommermonaten ein beliebtes Pendant zum Wintersport. Doch steile Berghänge zu meistern erfordert einiges an Zeit und Beinarbeit. Wie konnte die breite Bevölkerung dennoch etwas gegen das Wundern und für die Gesundheit tun?

Eine Antwort hiess: Gehlift. Nachdem im Winter 1934/35 der erste Skilift der Welt in Davos seinen Betrieb aufgenommen hatte, schossen in zahlreichen alpinen Feriendestinationen Schlepplifte aus dem Boden. Den Winter über transportierten sie Skifahrerinnen und Skifahrer, doch im Sommer standen sie unnütz herum. Dabei war es einfach, die Geschwindigkeit der Lifte um ein Drittel zu verringern und die Bügel oder Ledergürtel als Halte-, Zieh- oder Schiebevorrichtung für Fussgängerinnen und Fussgänger einzusetzen.

Zermatt machte im Sommer 1944 den Anfang mit einem umfunktionierten Skilift nach Sunnegga. Die anderthalb Kilometer lange Strecke wies die beachtliche Höhendifferenz von 680 Metern auf, die Steigung betrug an manchen Orten über $80 \%$. «Die Fussgänger können damit die Hebungsarbeit dem Lift überlassen, während ihr Gehwerk nur auf die Erhaltung der Gleichgewichtslage des Körpers bedacht sein muss", schwärmte die Schweizerische Bauzeitung. Die Fotografie (Abb. 1) zeigt einen Herrn mit Bundhosen, Wander-

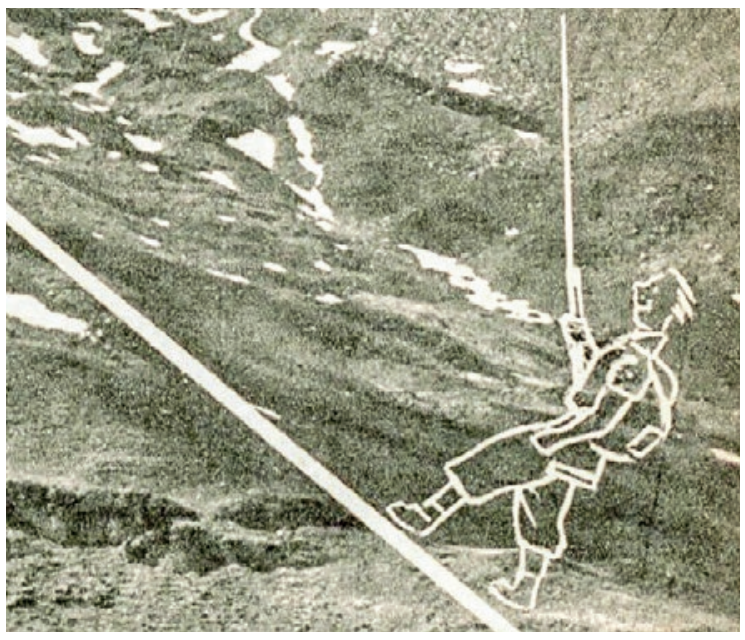

Abbildung 2: Zeichnung des Gehlifts auf den Jochpass.

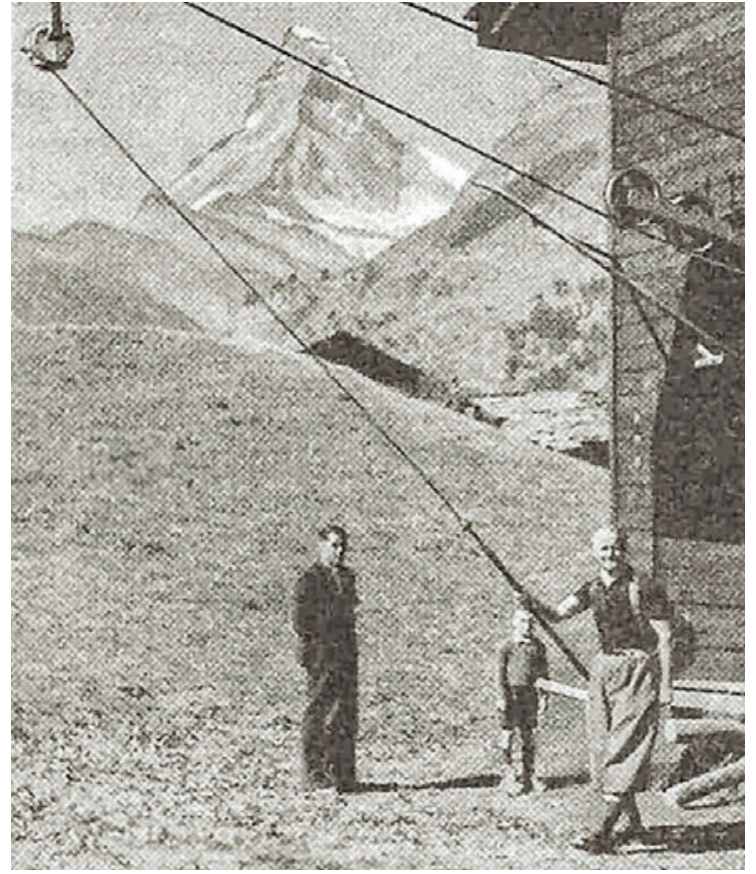

Abbildung 1: Fotografie des Gehlifts nach Sunnegga.

schuhen und Rucksack, der sich mit der rechten Hand am Griff festhält, während er vom hölzernen Bügel vorwärts geschoben wird. Das Matterhorn im Bildhintergrund versteht sich in der Zeit des Zweiten Weltkriegs als Ikone der heilen Bergwelt.

Im selben Sommer nahm ein zweiter Gehlift in der Region Engelberg seinen Betrieb auf. Er führte die Feriengäste vom Trübsee in zwanzig Minuten auf den Jochpass. Der Katalog der Reisekasse Reka widmete dem neuen Transportmittel eine ganze Seite. Auf dem Bild ist die herrliche Berglandschaft zu sehen, in die der Gehlift schematisch eingezeichnet wurde (Abb. 2). Analog zur Fotografie des Zermatter Prototyps lässt sich auch hier ein Wandersmann entspannt nach oben ziehen. «Ohne durch den mühsamen Aufstieg sich abzumüden» könne nun jedermann «vollständig frisch» eine Höhenwanderung starten, heisst es im Katalog. Noch im selben Sommer erfuhr dieser Gehlift eine Ergänzung mit Einersesseln. Dieser erste Sessellift Europas läutete eine neue Epoche der Bergerschliessung ein, führte aber zugleich zur Aufhebung des Gehlifts. Und so warten gehwillige, doch wenig trainierte Wandersleute - wundernd oder nicht - weiterhin auf Anschub in den Schweizer Bergen. 